\title{
Long-Term Efficacy and Safety Outcomes After Unrestricted Use of Drug-Eluting Stents in Patients With Acute Coronary Syndrome - Mortality and Major Bleeding in a Single-Center Registry -
}

Tetsuma Kawaji, MD; Hiroki Shiomi, MD; Takeshi Morimoto, MD, PhD; Toshihiro Tamura, MD; Ryusuke Nishikawa, MD; Mariko Yano, MD; Junichi Tazaki, MD; Masao Imai, MD; Naritatsu Saito, MD; Takeru Makiyama, MD; Satoshi Shizuta, MD; Koh Ono, MD; Takeshi Kimura, MD

\begin{abstract}
Background: Recent randomized clinical trials have reported favorable clinical outcomes after the use of drugeluting stents (DES) in patients with acute coronary syndrome (ACS). However, the long-term efficacy and safety outcomes, bleeding outcome in particular, after DES implantation in ACS patients have not been thoroughly evaluated in a real-world population.
\end{abstract}

\begin{abstract}
Methods and Results: We evaluated long-term clinical outcomes in 565 consecutive ACS patients who underwent DES implantation in an emergency setting between 2004 and 2011 (ST-segment elevation acute myocardial infarction [STEMI]: $n=269$, non-STEMI/unstable angina pectoris: $n=296$ ). Mean clinical follow-up period in this study was $4.6 \pm 2.0$ years. The cumulative incidence of all-cause death, cardiac death, myocardial infarction, stent thrombosis and targetlesion revascularization was $6.9 \%, 4.0 \%, 2.2 \%, 1.3 \%$ and $8.4 \%$ at 1 year, and $19.6 \%, 6.7 \%, 5.6 \%, 3.0 \%$ and $13.9 \%$ at 5 years, respectively. The cumulative 5 -year incidence of major bleeding events was $8.4 \%(n=42)$. Fatal bleeding events, however, occurred in only 4 patients, even including 2 patients who required resuscitation upon arrival at the hospital. Of the 42 patients with major bleeding events, 39 were taking dual antiplatelet therapy (DAPT) at the time of bleeding.
\end{abstract}

Conclusions: DES implantation provided favorable long-term clinical outcomes with an acceptably low incidence of fatal bleeding in a real-world population of ACS patients. However, prolonged DAPT seems to be associated with major bleeding after DES implantation. (Circ J 2014; 78: 1628-1635)

Key Words: Acute coronary syndrome; Bleeding; Drug-eluting stents

$\mathbf{R}$ ecent randomized clinical trials comparing secondgeneration drug-eluting stents (DES) with bare-metal stents (BMS) in patients with acute myocardial infarction (MI) have reported comparable safety outcomes, as well as with a significant reduction of target-lesion revascularization (TLR) in DES patients. ${ }^{1,2}$ Reflecting these study results, DES use in the setting of acute coronary syndrome (ACS) has become more common in daily clinical practice. For ACS patients receiving DES, the current guidelines recommend prolonged duration of dual antiplatelet therapy (DAPT), although adequate assessment of bleeding risk might be difficult in the setting of emergency PCI. ${ }^{3}$ However, the long-term bleeding outcome after DES implantation in real-world ACS patients has not been thoroughly evaluated yet.

To address this issue, the current single center study sought to evaluate the long-term efficacy and safety outcomes, including the incidence of major bleeding, after unrestricted use of DES in the setting of emergency PCI for ACS patients.

\section{Study Population}

Between September 2004 and December 2011, 613 patients were admitted to Kyoto University Hospital with a clinical diagnosis of ACS and underwent emergency PCI. ACS was defined as ST-segment elevation acute myocardial infarction

Received November 12, 2013; accepted March 19, 2014; released online May 14, 2014 Time for primary review: 35 days

Department of Cardiovascular Medicine, Graduate School of Medicine, Kyoto University, Kyoto (T. Kawaji, H.S., R.N., M.Y., J.T., M.I.,

N.S., T. Makiyama, S.S., K.O., T. Kimura); Division of General Medicine, Department of Internal Medicine, Hyogo College of Medicine,

Nishinomiya (T. Morimoto); and Department of Cardiovascular Medicine, Tenri Hospital, Tenri (T.T.), Japan

Mailing address: Hiroki Shiomi, MD, Department of Cardiovascular Medicine, Graduate School of Medicine, Kyoto University, 54 Shogoin

Kawahara-cho, Sakyo-ku, Kyoto 606-8507, Japan. E-mail: hishiomi@kuhp.kyoto-u.ac.jp

ISSN-1346-9843 doi:10.1253/circj.CJ-13-1388

All rights are reserved to the Japanese Circulation Society. For permissions, please e-mail: cj@j-circ.or.jp 
(STEMI), ${ }^{3}$ non-STEMI, or unstable angina pectoris (UAP). UAP fulfilled the following criteria: worsening typical angina without myocardial enzyme elevation, and culprit lesions confirmed using coronary angiography with emergency PCI for the culprit lesions. The vast majority of patients received DES $(\mathrm{n}=565,92.2 \%)$ as the default strategy, and a limited number of patients received BMS $(n=34,5.5 \%)$ because of the high bleeding risk, malignant disease, or anticipated major surgery, etc. After excluding 48 patients with BMS implantation $(n=34)$ or without stent implantation $(n=14)$, the study population consisted of 565 consecutive ACS patients who underwent PCI using DES in an emergency setting at the hospital (Figure 1). Written informed consent for the procedure and follow-up protocol was given by all patients before the procedure was performed.

\section{Antithrombotic Therapy}

The recommended loading dose of aspirin and clopidogrel before PCI were $162 \mathrm{mg}$ and $600 \mathrm{mg}$, respectively. Unfractionated heparin was used to keep activated clotting time during PCI at $>250$ s. The recommended maintenance antiplatelet therapy regimen was aspirin ( $\geq 81 \mathrm{mg}$ daily) indefinitely and thienopyridines ( $75 \mathrm{mg}$ clopidogrel or $200 \mathrm{mg}$ ticlopidine daily) for at least 3 months after DES implantation. Duration of DAPT was left to the discretion of the attending physicians. Dates of discontinuation of aspirin and thienopyridines were reported separately during follow-up. If either aspirin or the thienopyridine was restarted after discontinuation, the dates of restarting were also recorded. Persistent discontinuation of thienopyridines was defined as withdrawal lasting at least 2 months.

\section{Definitions and Endpoints}

Demographic, angiographic, and procedural data were collected from hospital charts according to prespecified definitions. The outcome measures evaluated in this study included all-cause death, cardiac death, MI, definite ST, stroke, TLR, any coronary revascularization, and major bleeding.

Death was regarded as cardiac in origin unless an obvious non-cardiac cause could be identified. MI was defined according to the definition in the Arterial Revascularization Therapy Study. ${ }^{4}$ ST was defined according to the Academic Research Consortium (ARC) definition. ${ }^{5}$ Stroke during follow-up was defined as ischemic or hemorrhagic stroke requiring hospitalization with symptoms lasting $>24 \mathrm{~h}$. TLR was defined as either PCI or CABG for restenosis or thrombosis of the culprit lesion of ACS. Any coronary revascularization was defined as either PCI or CABG for any reason. Major bleeding was defined as moderate or severe bleeding by Global Utilization of Streptokinase and Tissue plasminogen activator for Occluded coronary arteries (GUSTO) classification. ${ }^{6}$

Follow-up information was obtained by hospital-chart review and/or telephone contact with the patient, relatives, or referring practitioners. The mean clinical follow-up period was $4.6 \pm 2.0$ years.

\section{Statistical Analysis}

Continuous variables are presented as mean \pm standard deviation or median with interquartile range, and were compared using Student's t-test or Wilcoxon rank sum test based on their distributions. Categorical variables are presented as number and percentage and compared with the chi-square test. We used the Kaplan-Meier method to estimate the cumulative incidences of clinical events and assessed the difference with the log-rank test. Multivariable analyses using the Cox proportional hazard model were conducted to identify independent risk factors for

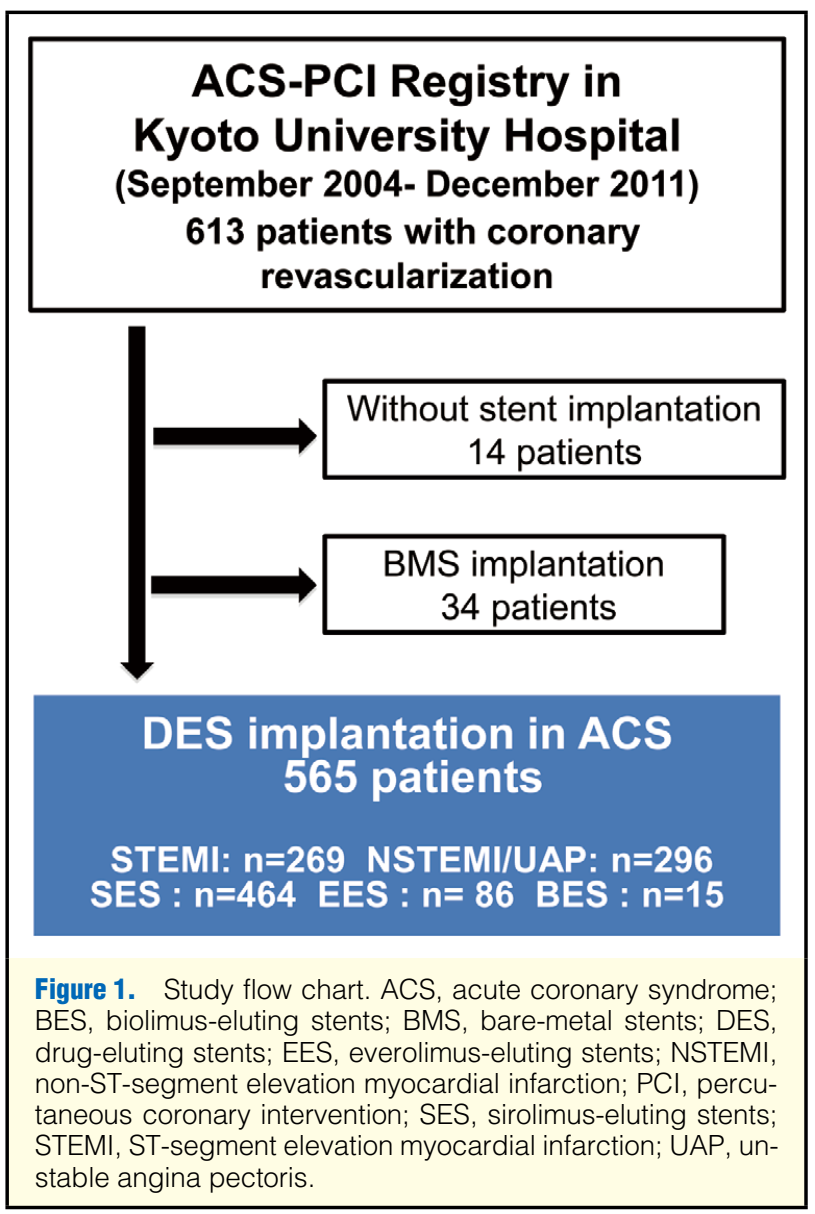

all-cause death and major bleeding. Potential independent variables in the Cox proportional hazard models for all-cause death and major bleeding are shown in Table $\mathbf{1}$ and Table S1, respectively. Continuous variables were dichotomized by clinically meaningful reference values or median values. Regarding bleeding events, clinical and procedural characteristics were compared between patients with and without major bleeding. Furthermore, we conducted a 1-year landmark analysis to assess the relation between DAPT status at 1 year and long-term bleeding risk. Statistical analyses were performed using JMP 10 (SAS Institute Inc, Cary, NC, USA) software. All analyses were 2-tailed, and $\mathrm{P}<0.05$ was considered statistically significant.

\section{Results}

\section{Baseline Patients Characteristics}

The current study population was characterized by a high prevalence of patients with advanced age and coronary risk factors, such as hypertension, dyslipidemia, and diabetes mellitus (Table 1). A history of previous PCI and MI was obtained for $13 \%$ and $12 \%$, respectively. The majority of the patients had preserved left ventricular (LV) systolic function, and only $11 \%$ of patients had reduced LV ejection fraction $(\leq 40 \%)$. Patients with a high bleeding risk such as anemia (hemoglobin $\leq 11 \mathrm{~g} / \mathrm{dl}$ ), history of gastrointestinal (GI) bleeding, and malignancy were $18 \%, 1.4 \%$, and $14 \%$, respectively (Table 1 ).

Admission diagnosis of ACS included STEMI (48\%), nonSTEMI (18\%), and UAP (35\%). Regarding procedural char- 


\begin{tabular}{|c|c|}
\hline & $n=565$ \\
\hline \multicolumn{2}{|l|}{ Clinical characteristics } \\
\hline Age (years) & $69.5 \pm 11.8$ \\
\hline Age $\geq 75$ years $^{*}$ & $204(36 \%)$ \\
\hline Male & $392(69 \%)$ \\
\hline Hypertension & $405(72 \%)$ \\
\hline Dyslipidemia & $289(51 \%)$ \\
\hline Diabetes mellitus & $196(35 \%)$ \\
\hline Current smoking & $145(26 \%)$ \\
\hline Previous MI & $68(12 \%)$ \\
\hline Previous stroke ${ }^{*}$ & $82(15 \%)$ \\
\hline Previous $\mathrm{PCl}$ & $75(13 \%)$ \\
\hline Previous DES & $19(3.4 \%)$ \\
\hline Previous $\mathrm{CABG}^{*}$ & $14(2.5 \%)$ \\
\hline eGFR $\leq 30\left(\mathrm{ml} \cdot \mathrm{min}^{-1} \cdot 1.73 \mathrm{~m}^{-2}\right)^{\star}$ & $52(9.2 \%)$ \\
\hline Hemodialysis & $31(5.5 \%)$ \\
\hline $\mathrm{AF}^{\star}$ & $40(7.1 \%)$ \\
\hline $\mathrm{CHADS}_{2}(\mathrm{n}=40)$ & $2.4 \pm 2.1$ \\
\hline $\mathrm{CHA}_{2} \mathrm{DS}_{2}$-VASc $(\mathrm{n}=40)$ & $5.0 \pm 2.6$ \\
\hline HAS-BLED $(n=40)$ & $3.2 \pm 1.1$ \\
\hline LVEF & $59.2 \pm 12.8$ \\
\hline$\leq 40(\%)^{*}$ & $62(11 \%)$ \\
\hline Hemoglobin $\leq 11(\mathrm{~g} / \mathrm{dl})^{*}$ & $100(18 \%)$ \\
\hline Platelet count $\leq 100,000(\mu / L)^{*}$ & $16(2.8 \%)$ \\
\hline Previous GI bleeding & $8(1.4 \%)$ \\
\hline Malignancy* & $80(14 \%)$ \\
\hline \multicolumn{2}{|c|}{$\begin{array}{l}\text { Clinical presentation and procedural } \\
\text { characteristics }\end{array}$} \\
\hline Killip class $\geq 3^{*}$ & $46(8.1 \%)$ \\
\hline STEMI & $269(48 \%)$ \\
\hline NSTEMI & $100(18 \%)$ \\
\hline LAD culprit ACS & $292(52 \%)$ \\
\hline
\end{tabular}

acteristics, multiple stenting was performed in $41 \%$ of patients. Sirolimus-eluting, everolimus-eluting and biolimus-eluting stents were used in $82 \%, 15 \%$, and $2.7 \%$ of patients, respectively (Table 1 ).

The vast majority of patients were prescribed DAPT at the time of hospital discharge. Evidence-based medicines, such as statins, $\beta$-blockers, and angiotensin-converting enzyme inhibiters (ACEI)/angiotensin receptor blockers (ARB), were utilized in $83 \%, 51 \%$, and $67 \%$ of patients, respectively.

\section{Cardiovascular Outcomes}

The cumulative incidence of all-cause death was $2.7 \%$ at 30 days, $6.9 \%$ at 1 year, and $19.6 \%$ at 5 years (Figure $2 \mathrm{~A}$ ). Cardiac death accounted for only one-third of all-cause deaths during the 5-year follow-up period. The cumulative 5-year incidence of MI was $5.6 \%$ and the cumulative incidence of stroke was $5.9 \%$ (Figures 2B,C). Definite ST occurred in 6 patients $(1.1 \%$ ) at 30 days, in 7 patients $(1.3 \%)$ at 1 year, and 14 patients $(3.0 \%)$ at 5 years. The annual rate of very late ST beyond 1 year after stent implantation was $0.4 \%$ year (Figure 2B). The cumulative incidence of TLR was $1.6 \%$ at 30 days, $8.4 \%$ at 1 year, and $13.9 \%$ at 5 years (Figure 2D). In the current study, follow-up angiography was performed in 352 patients $(64.1 \%)$ within 1 year of DES implantation.

The independent risk factors for all-cause death included age

\begin{tabular}{|lc|} 
Stent thrombosis or restenosis (culprit & $21(3.7 \%)$ \\
lesion) & \\
Multivessel disease & $164(29 \%)$ \\
Sirolimus-eluting stent & $464(82 \%)$ \\
Everolimus-eluting stent & $86(15 \%)$ \\
Biolimus-eluting stent & $15(2.7 \%)$ \\
Total number of stents $\geq 2$ & $232(41 \%)$ \\
Total stent length $\geq 50(\mathrm{~mm})$ & $147(26 \%)$ \\
Maximum CK value & $1,480(1,291-1,670)$ \\
$\geq 1,000$ (IU/L) & $208(27 \%)$ \\
Medications at discharge & \\
Aspirin & $564(99.8 \%)$ \\
Thienopyridines & $561(99.3 \%)$ \\
Ticlopidine & $179(32 \%)$ \\
Clopidogrel & $373(66 \%)$ \\
Cilostazol & $16(2.8 \%)$ \\
Statin* & $467(83 \%)$ \\
$\beta$-blocker* & $290(51 \%)$ \\
ACEI/ARB* & $379(67 \%)$ \\
Nitrate* & $122(22 \%)$ \\
Calcium-channel blocker & $178(32 \%)$ \\
Warfarin* & $49(8.7 \%)$ \\
PPI & $389(69 \%)$ \\
H2 blocker & $48(8.5 \%)$ \\
\hline Datarenumber & \\
\hline
\end{tabular}

Data are number of patients (prevalence). Continuous variables are presented as mean \pm SD. *Potential independent variables selected for the Cox proportional hazard model (all-cause death). ACEI/ARB, angiotensin-converting enzyme inhibitor/angiotensin receptor blocker; ACS, acute coronary syndrome; $\mathrm{AF}$, atrial fibrillation; $\mathrm{CABG}$, coronary artery bypass grafting; $\mathrm{CK}$, creatine kinase; DES, drug-eluting stents; eGFR, estimated glomerular filtration rate; Gl, gastrointestinal; $\mathrm{H} 2$ blocker, histamine $\mathrm{H} 2$ receptor blocker; $L A D$, left anterior descending artery; LVEF, left ventricular ejection fraction; $\mathrm{MI}$, myocardial infarction; $\mathrm{PCl}$, percutaneous coronary intervention; PPI, proton-pump inhibitor; STEMI, ST-segment elevation myocardial infarction; NSTEMI, non-STEMI. $\geq 75$ years (hazard ratio [HR]: $3.25,95 \%$ confidence interval [CI]: 2.15-5.01, $\mathrm{P}<0.001$ ), hemoglobin $\leq 11 \mathrm{~g} / \mathrm{dl}$ (HR: $1.95,95 \%$ CI: $1.24-3.04, \mathrm{P}=0.04$ ), Killip class $3 / 4$ on admission (HR: 2.21, 95\% CI: $1.20-3.95, \mathrm{P}=0.01)$, maximum creatine kinase $\geq 1,000$ IU/L (HR: $2.05,95 \%$ CI: $1.33-3.14, \mathrm{P}=0.001$ ), statins (HR: 0.53, 95\% CI: 0.35-0.82, $\mathrm{P}=0.004), \beta$-blockers (HR: 0.50, 95\% CI: $0.33-0.76, \mathrm{P}=0.001$ ), ACEI/ARB (HR: 0.49, 95\% CI: $0.33-0.73, \mathrm{P}<0.001)$, and nitrate (HR: $0.57,95 \% \mathrm{CI}: 0.32-0.96$, $\mathrm{P}=0.04$ ) (Table 2).

\section{Bleeding Outcomes}

Major bleeding occurred in 18 patients (3.0\%) at 30 days, in $29(5.2 \%)$ at 1 year, and $42(8.4 \%)$ at 5 years (Figure $2 \mathrm{E}$ ). Of the 42 patients who suffered from major bleeding, procedurerelated bleeding occurred in $9(21 \%)$, GI bleeding in $16(38 \%)$, and hemorrhagic stroke in $10(24 \%)$ (Figure 3). The incidence of GI bleeding and hemorrhagic stroke gradually increased over time. Among the 16 patients who experienced GI bleeding, the bleeding site included the lower GI in 9 patients, and 8 of them were diagnosed as having polyp or cancer after bleeding (Figure 4A). Among the 10 patients with hemorrhagic stroke, acute intracranial hemorrhage occurred in 6 , chronic subdural hematoma in 2, subarachnoid hemorrhage in 1, and hemorrhagic infarction in 1 (Figure 4B). Fatal bleeding occurred in only 4 patients, comprising procedure-related bleeding events 


\section{A) All-cause death / cardiac death}

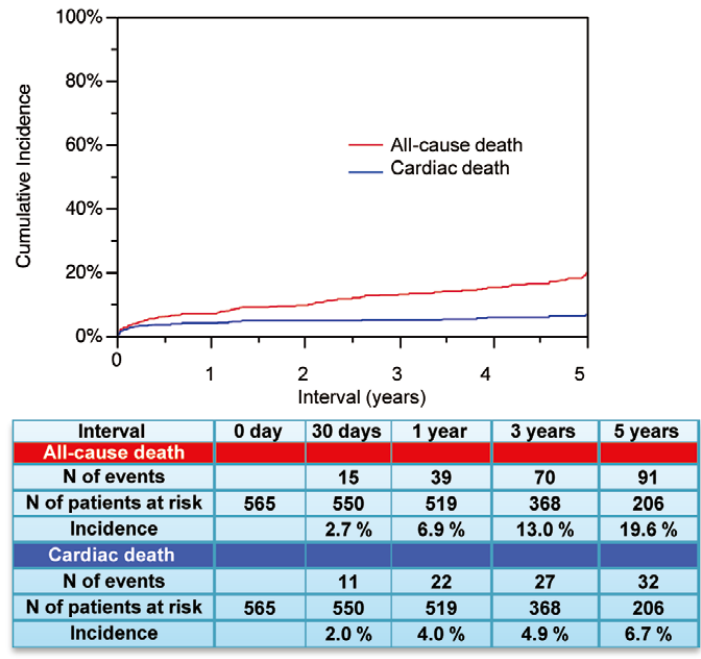

C) Stroke

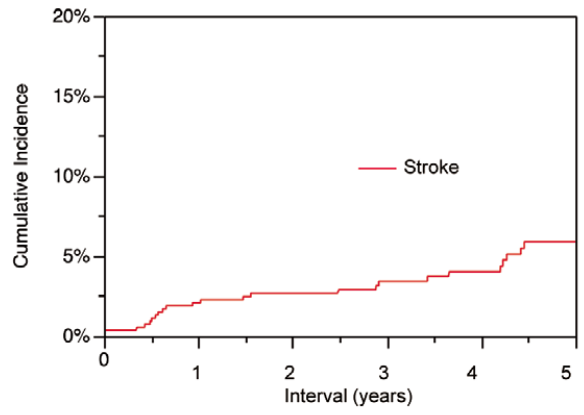

\begin{tabular}{|c|c|c|c|c|c|}
\hline Interval & 0 day & 30 days & 1 year & 3 years & 5 years \\
\hline $\begin{array}{c}\text { Stroke } \\
\text { N of events }\end{array}$ & & 2 & 11 & 17 & 24 \\
\hline N of patients at risk & 565 & 550 & 511 & 359 & 197 \\
\hline Incidence & & $0.35 \%$ & $2.1 \%$ & $3.4 \%$ & $5.9 \%$ \\
\hline
\end{tabular}

\section{E) Major bleeding}

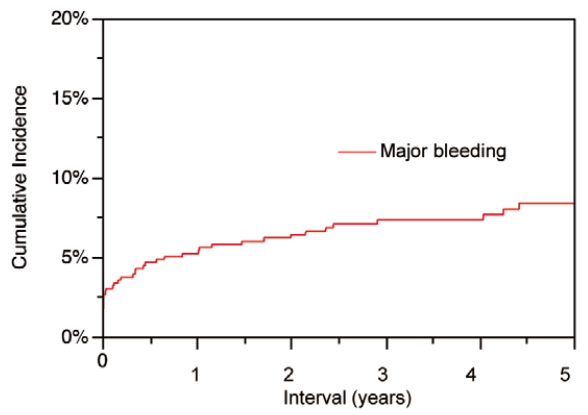

\begin{tabular}{|c|c|c|c|c|c|}
\hline Interval & 0 day & $\mathbf{3 0}$ days & $\mathbf{1}$ year & 3 years & $\mathbf{5}$ years \\
\hline $\begin{array}{c}\text { Major Bleeding } \\
\text { N of events }\end{array}$ & & 18 & 29 & 39 & 42 \\
\hline N of patients at risk & 565 & 540 & 503 & 353 & 191 \\
\hline Incidence & & $3.0 \%$ & $5.2 \%$ & $7.3 \%$ & $8.4 \%$ \\
\hline
\end{tabular}

B) Myocardial Infarction / Stent Thrombosis

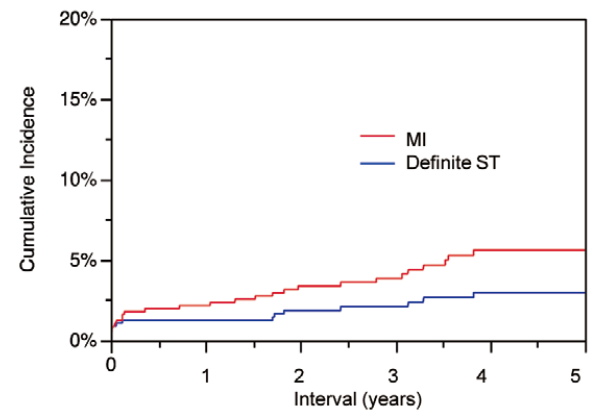

\begin{tabular}{|c|c|c|c|c|c|}
\hline Interval & 0 day & 30 days & 1 year & 3 years & 5 years \\
\hline MI & & & & & \\
\hline $\mathrm{N}$ of events & & 7 & 12 & 20 & 26 \\
\hline $\mathrm{N}$ of patients at risk & 565 & 546 & 514 & 360 & 197 \\
\hline Incidence & & $1.3 \%$ & $2.2 \%$ & $3.9 \%$ & $5.6 \%$ \\
\hline \multicolumn{6}{|l|}{ Definite ST } \\
\hline $\mathrm{N}$ of events & & 6 & 7 & 11 & 14 \\
\hline $\mathrm{N}$ of patients at risk & 565 & 546 & 515 & 365 & 202 \\
\hline Incidence & & $1.1 \%$ & $1.3 \%$ & $2.1 \%$ & $3.0 \%$ \\
\hline
\end{tabular}

\section{D) Coronary revascularization}

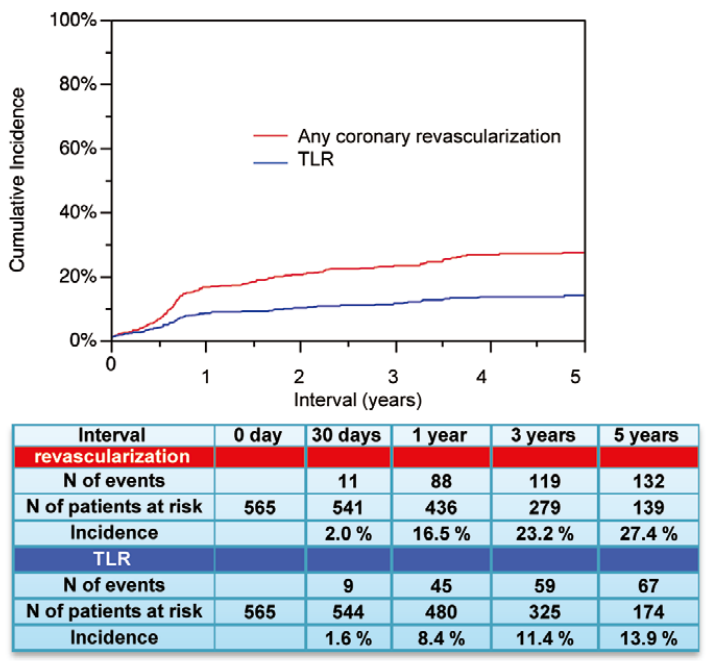

Figure 2. Kaplan-Meier event curves for (A) all-cause death and cardiac death, (B) myocardial infarction (MI) and definite stent thrombosis (ST), (C) stroke, (D) target-lesion revascularization (TLR) and any coronary revascularization, and (E) major bleeding. 
Table 2. Independent Risk Factors for All-Cause Death Through 5-Year Follow-up of ACS Patients With DES

\begin{tabular}{|c|c|c|c|c|c|c|c|c|}
\hline \multirow[t]{2}{*}{ Variables } & \multicolumn{2}{|c|}{$\begin{array}{l}\text { No. of events/No. of patients } \\
\text { (cumulative incidence) }\end{array}$} & \multicolumn{3}{|c|}{ Univariate } & \multicolumn{3}{|c|}{ Multivariable } \\
\hline & Present & Absent & HR & $95 \% \mathrm{Cl}$ & $P$ value & HR & $95 \% \mathrm{Cl}$ & $P$ value \\
\hline Age $\geq 75$ years & $59 / 204(35.3 \%)$ & $32 / 361(11.0 \%)$ & 4.25 & $2.87-6.40$ & $<0.001$ & 3.25 & $2.13-5.01$ & $<0.001$ \\
\hline Previous stroke & $24 / 82(29.3 \%)$ & $84 / 483(17.4 \%)$ & 1.74 & $1.08-2.69$ & 0.02 & 1.55 & $0.94-2.47$ & 0.09 \\
\hline Previous CABG & $5 / 14(43.4 \%)$ & $86 / 551(19.0 \%)$ & 2.60 & $1.02-5.44$ & 0.047 & 1.88 & $0.72-4.09$ & 0.18 \\
\hline eGFR $\leq 30 \mathrm{ml} \cdot \mathrm{min}^{-1} \cdot 1.73 \mathrm{~m}^{-2}$ & $24 / 52(51.8 \%)$ & $67 / 513(15.6 \%)$ & 4.11 & $2.66-6.19$ & $<0.001$ & 1.58 & $0.94-2.61$ & 0.09 \\
\hline AF & $13 / 40(42.3 \%)$ & $78 / 525(17.9 \%)$ & 2.30 & $1.25-3.90$ & 0.009 & 0.63 & $0.29-1.28$ & 0.21 \\
\hline LVEF $\leq 40 \%$ & $25 / 62(44.7 \%)$ & $66 / 503(16.4 \%)$ & 3.03 & $1.91-4.64$ & $<0.001$ & 1.73 & $0.94-3.09$ & 0.08 \\
\hline Hemoglobin $\leq 11$ (g/dl) & $33 / 100(38.2 \%)$ & $58 / 465(15.6 \%)$ & 2.90 & $1.93-4.27$ & $<0.001$ & 1.95 & $1.24-3.04$ & 0.04 \\
\hline Platelet count $\leq 100,000(\mu / \mathrm{L})$ & $5 / 16(34.3 \%)$ & $86 / 549(19.2 \%)$ & 2.61 & $1.10-5.22$ & 0.03 & 1.05 & $0.43-2.17$ & 0.91 \\
\hline Malignancy & $22 / 80(27.5 \%)$ & $86 / 485(17.7 \%)$ & 1.66 & $1.01-2.60$ & 0.045 & 1.11 & $0.64-1.84$ & 0.70 \\
\hline Killip class $\geq 3$ & $22 / 46(53.7 \%)$ & $69 / 519(16.7 \%)$ & 4.15 & $2.54-6.51$ & $<0.001$ & 2.21 & $1.20-3.95$ & 0.01 \\
\hline Maximum $\mathrm{CK}$ value $\geq 1,000$ (IU/L) & $44 / 208(25.3 \%)$ & $47 / 357(16.3 \%)$ & 1.60 & $1.09-2.33$ & 0.02 & 2.05 & $1.33-3.14$ & 0.001 \\
\hline Statin & $62 / 467(13.3 \%)$ & $46 / 98(46.9 \%)$ & 0.28 & $0.19-0.41$ & $<0.001$ & 0.53 & $0.35-0.82$ & 0.004 \\
\hline$\beta$-blocker & $41 / 290(14.1 \%)$ & $67 / 275(24.4 \%)$ & 0.57 & $0.39-0.84$ & 0.004 & 0.50 & $0.33-0.76$ & 0.001 \\
\hline ACEI/ARB & $55 / 379(14.5 \%)$ & $53 / 186(28.5 \%)$ & 0.48 & $0.33-0.70$ & $<0.001$ & 0.49 & $0.33-0.73$ & $<0.001$ \\
\hline Nitrate & $16 / 122(13.1 \%)$ & $92 / 443(20.8 \%)$ & 0.49 & $0.28-0.81$ & 0.005 & 0.57 & $0.32-0.96$ & 0.04 \\
\hline Warfarin & $19 / 49$ (38.8\%) & $89 / 516(17.3 \%)$ & 2.36 & $1.39-3.78$ & 0.002 & 1.56 & $0.80-2.94$ & 0.19 \\
\hline
\end{tabular}

Cumulative incidence of all-cause death at 5 -year was estimated by the Kaplan-Meier method.

$\mathrm{Cl}$, confidence interval; HR, hazard ratio. Other abbreviations as in Table 1.

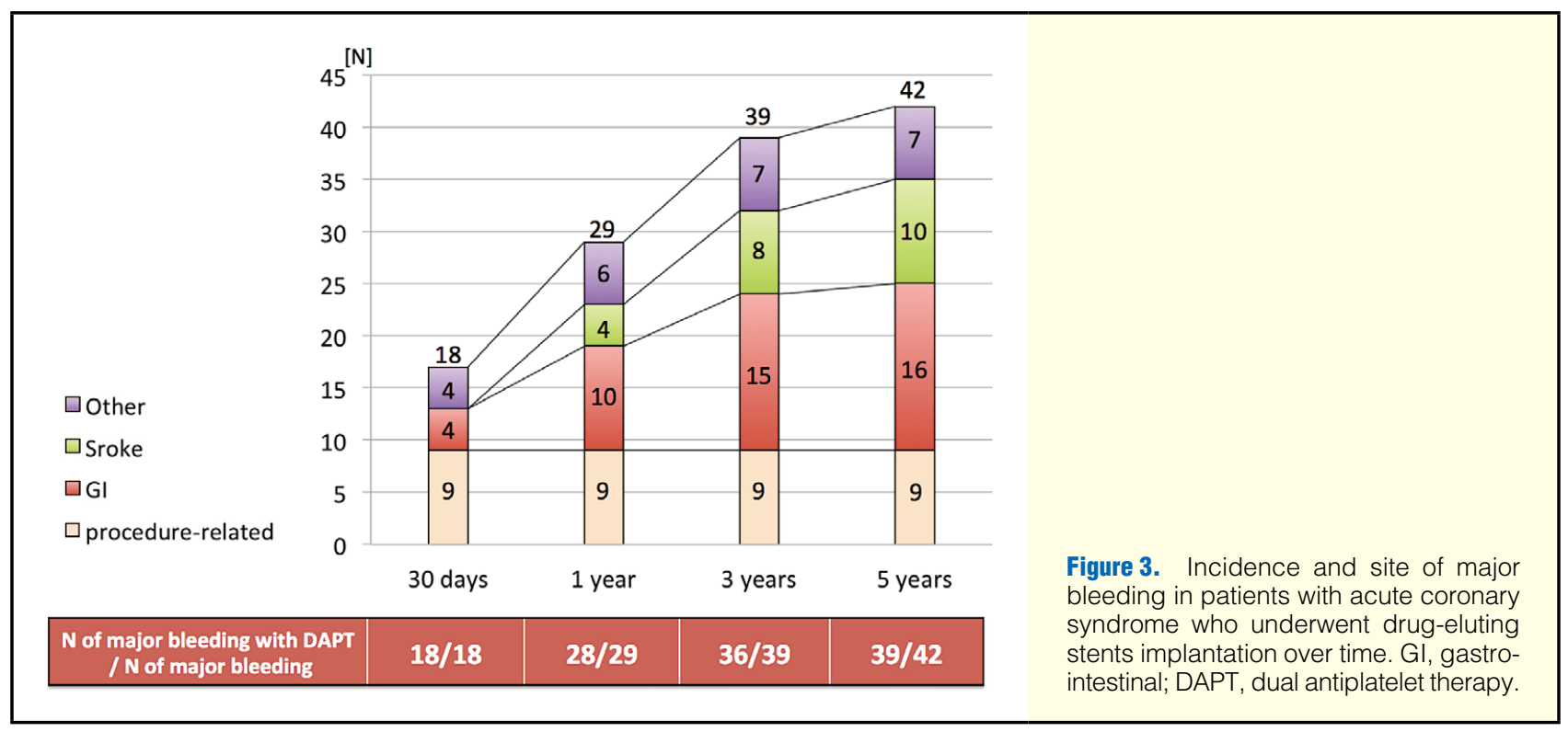

in 3 patients ( 2 patients who were resuscitated upon admission) and a GI bleeding event in 1 patient.

Regarding the status of DAPT at the time of bleeding, 39 of 42 patients with major bleeding was receiving DAPT at the time of bleeding, and almost half of the entire study population had continued DAPT at 1 year (Figure 5). Of the 13 patients with major bleeding beyond 1 year after DES implantation, 11 continued to receive DAPT (including 2 patients receiving triple therapy with DAPT and warfarin). Of the 39 patients who suffered from major bleeding with DAPT, 22 patients discontinued either the thienopyridine or aspirin or both after the bleeding event (temporary discontinuation: $\mathrm{n}=11$, persistent discontinuation: $n=11$ ). However, none of these patients suffered from ST or MI after discontinuation of DAPT, including 12 patients who discontinued DAPT within 1 year after DES implantation for ACS.

The baseline patients characteristics with and without major bleeding are shown in Table S1. Compared with the patients without major bleeding, the patients with major bleeding were older, and had a higher prevalence of anemia and heart failure on admission, STEMI presentation, and the culprit lesion in the LAD. None of the patients with major bleeding had a history of DES implantation before admission. Regarding the potential factors associated with bleeding risk, the prevalence of history of GI bleeding and malignancy were not significantly different between the 2 groups (Table $\mathbf{S} 1$ ). The prescription rates of both proton-pump inhibitors (PPI) and histamine $\mathrm{H} 2$ receptor blockers were also not different between the 2 groups (Table $\mathbf{S 1}$ ).

The independent risk factors for major bleeding included hemoglobin $\geq 11 \mathrm{~g} / \mathrm{dl}$ (HR: 2.52 , 95\% CI: $1.25-4.90, \mathrm{P}=0.01$ ), 
A)

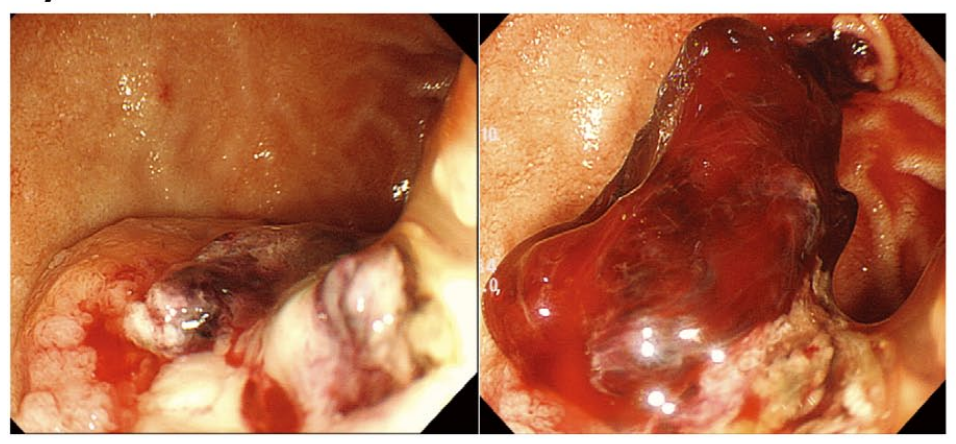

B)

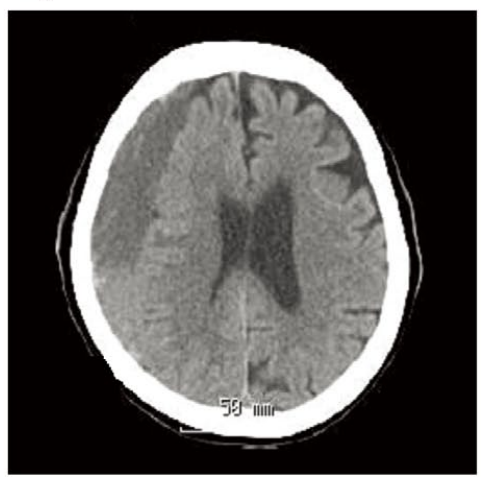

Figure 4. Representative major bleeding events after drug-eluting stent (DES) implantation. (A) Gastrointestinal bleeding from duodenal cancer 127 days after DES implantation: 76-year-old woman who received a DES for the diagnosis of ST-segment elevation myocardial infarction (STEMI) suffered from melena and anemia 127 days after DES implantation. She was continuing with dual antiplatelet therapy (DAPT) in combination with warfarin at the time of bleeding. Duodenal cancer was detected using esophagogastroduodenoscopy, and she was successfully treated with neoadjuvant chemotherapy and surgery. (B) Hemorrhagic stroke 1,064 days after DES implantation: 80-year-old woman who had received a DES in the setting of STEMI presented with loss of consciousness 1,064 days after DES implantation while on prolonged DAPT. A chronic subdural hematoma was detected by computed tomography. She was successfully treated with emergency trepanation surgery.

\section{DAPT discontinuation}

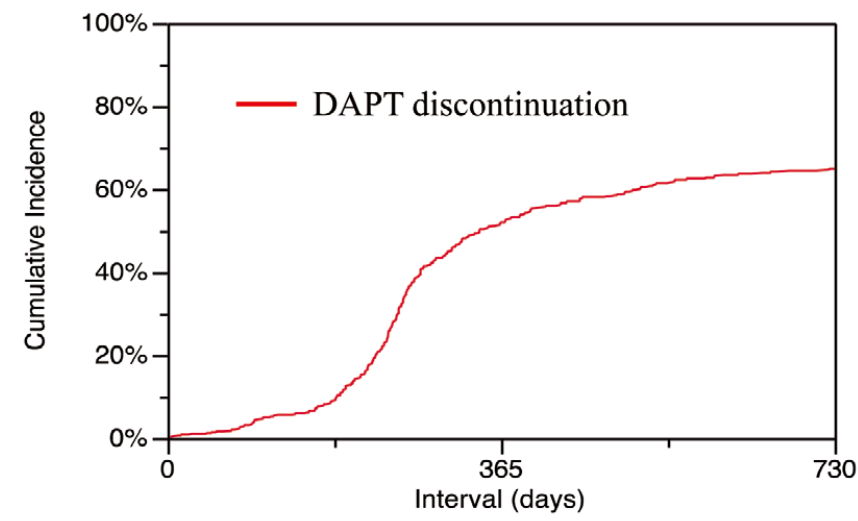

\begin{tabular}{|c|c|c|c|c|c|}
\hline $\begin{array}{c}\text { Interval } \\
\text { DAPT discontinuation }\end{array}$ & day & $\mathbf{3 0}$ days & 180 days & 1 year & 2 years \\
\hline N of events & & 6 & 48 & 263 & 322 \\
\hline N of patients at risk & 565 & 538 & 466 & 234 & 140 \\
\hline Incidence & & $1.1 \%$ & $9.1 \%$ & $52 \%$ & $65 \%$ \\
\hline
\end{tabular}

Figure 5. Cumulative incidence of persistent discontinuation of dual antiplatelet therapy (DAPT); that is, withdrawal for more than 2 months of either aspirin or thienopyridine.
Killip class 3/4 on admission (HR: $3.08,95 \%$ CI: 1.40-6.25, $\mathrm{P}=0.008)$, STEMI (HR: 2.73, 95\% CI: 1.33-5.77, $\mathrm{P}=0.01$ ), and LAD culprit ACS (HR: 2.02. 95\% CI: 1.06-4.00, P=0.03) (Table 3).

\section{DAPT Duration and Bleeding Outcomes: Landmark Analysis at 1 Year}

After excluding 49 patients with clinical events within 1 year (death, major bleeding, and ST) and 16 patients lost to followup within 1 year, 500 patients were eligible for the 1-year landmark analysis. At 1 year after ACS, 249 patients (49.8\%) had continued DAPT, while 251 patients $(50.2 \%)$ had discontinued

\section{DAPT.}

The cumulative incidence of major bleeding between 1 and 5 years in the on-DAPT group tended to be higher than in the off-DAPT group ( $4.6 \%$ vs. $2.1 \%, \mathrm{P}=0.16$ ) (Figure $\mathrm{S1A}$ ). On the other hand, the cumulative incidence of ST between 1 and 5 years in the on-DAPT group was not lower than that in the off-DAPT group (2.5\% vs. $1.2 \%, \mathrm{P}=0.25)$ (Figure $\mathrm{S} 1 \mathrm{~B}$ ).

\section{Discussion}

The main findings of the current study include the following: (1) DES implantation in ACS patients resulted in favorable 
Table 3. Independent Risk Factors for Major Bleeding at 5 Years After DES for ACS

\begin{tabular}{|c|c|c|c|c|c|c|c|c|}
\hline \multirow[t]{2}{*}{ Variables } & \multicolumn{2}{|c|}{$\begin{array}{l}\text { No. of events/No. of patients } \\
\text { (cumulative incidence) }\end{array}$} & \multicolumn{3}{|c|}{ Univariate } & \multicolumn{3}{|c|}{ Multivariable } \\
\hline & Present & Absent & HR & $95 \% \mathrm{Cl}$ & $P$ value & HR & $95 \% \mathrm{Cl}$ & $P$ value \\
\hline Age $\geq 75$ & 22/204 (11\%) & $20 / 361(5.5 \%)$ & 2.18 & $1.19-4.03$ & 0.01 & 1.89 & $1.00-3.61$ & 0.06 \\
\hline Hemoglobin $\leq 11$ (g/dl) & $15 / 100(15 \%)$ & $27 / 465(5.8 \%)$ & 2.86 & $1.49-5.31$ & 0.002 & 2.52 & $1.25-4.90$ & 0.01 \\
\hline Killip class $\geq 3$ & $10 / 46(22 \%)$ & $32 / 519(6.2 \%)$ & 4.62 & $2.15-9.07$ & $<0.001$ & 3.08 & $1.40-6.25$ & 0.008 \\
\hline STEMI & $28 / 269$ (10\%) & $14 / 296(4.7 \%)$ & 2.33 & $1.24-4.54$ & 0.008 & 2.73 & $1.33-5.77$ & 0.01 \\
\hline LAD culprit ACS & 28/292 (9.6\%) & $14 / 273(5.1 \%)$ & 1.93 & $1.04-3.78$ & 0.04 & 2.02 & $1.06-4.00$ & 0.03 \\
\hline Maximum CK value $\geq 1,000$ (IU/L) & $21 / 208(10 \%)$ & $21 / 357(5.9 \%)$ & 1.85 & $1.01-3.41$ & 0.048 & 1.36 & $0.70-2.68$ & 0.37 \\
\hline Statin & $28 / 467(6.0 \%)$ & $14 / 98(14 \%)$ & 0.39 & $0.21-0.77$ & 0.007 & 0.62 & $0.31-1.29$ & 0.09 \\
\hline
\end{tabular}

Cumulative incidence of major bleeding at 5 years was estimated by the Kaplan-Meier method.

Abbreviations as in Tables 1,2.

short and long-term survival outcomes with a low rate of TLR even in real-world clinical practice; (2) the incidence of fatal bleeding was acceptably low despite the unrestricted use of DES in real-world clinical practice; and (3) most patients who suffered from major bleeding was receiving DAPT at the time of bleeding.

Several randomized trials comparing first-generation DES with BMS in ACS patients reported favorable results of DES more than 5 years ago. ${ }^{7-9}$ However, the role of DES in ACS patients remains controversial, although their use in ACS patients becoming widespread in daily clinical practice after the reporting of favorable clinical outcomes for second-generation DES use in patients with AMI., ${ }^{1,2}$ The updated 2013 ACCF/AHA Guideline for the Management of STEMI regards DES as a Class III indication in STEMI patients who cannot tolerate or comply with prolonged DAPT, and regards BMS as a Class I indication in STEMI patients with a high bleeding risk and an inability to comply with prolonged DAPT. ${ }^{3}$ Moreover, the guideline stresses the difficulty in determining emergently whether a patient is eligible for a prolonged course of DAPT. However, few data are available regarding the long-term clinical outcomes, bleeding outcome in particular, after DES implantation in ACS patients in real-world clinical practice. ${ }^{10}$

The current study evaluated the unrestricted DES use for ACS patients in real-world clinical practice, and found that DES implantation in ACS patients provided favorable short and longterm survival outcomes with a low rate of TLR even in a realworld clinical practice, and there were no apparent safety concerns with an acceptably low rate of definite ST. Consistent with previous reports from other countries, ${ }^{11}$ the CREDOKyoto registry cohort- 2 reported significantly lower cumulative incidence of TLR with comparable risk of definite ST after DES implantation compared with BMS implantation in patients with AMI in real-world practice (TLR at 3 years: $12.3 \%$ vs. $23.0 \%, \mathrm{P}<0.0001$, and definite ST at 3 years: $1.4 \%$ vs. $2.5 \%, \mathrm{P}=0.06$, respectively). ${ }^{12}$ However, only patients with low risk profiles tend to be selected as candidates for DES use in observational studies, which hampers assessment of the feasibility of DES in real-world clinical practice. From this point of view, the current study of unrestricted DES use for ACS patients showed a comparable low rate of definite ST even compared with that in BMS patients in the CREDO-Kyoto registry cohort-2, suggesting a comparable safety outcome of DES use in real-world clinical practice. Additionally, further improvement in decreasing ST would be expected in the current second-generation DES era. ${ }^{1}$

Bleeding events after PCI are a major concern with DES use in ACS patients. ${ }^{13-19}$ Previous studies have reported that in- hospital major bleeding after stent implantation for ACS occurred in approximately $3-5 \%$ of patients and was associated with a poor prognosis. ${ }^{19,20}$ In the current study, the cumulative incidence of 30-day and 5-year major bleeding was 3.0\% and $8.4 \%$, respectively. Approximately half of the bleeding events occurred in the perioperative period in the current study and the majority of bleeding events in this period related not to antithrombotic agents but to the procedure itself or the patient's critically ill status, and the constant risk for major bleeding beyond 1 year after ACS was also observed up to 5 years in the current study. Consistent with previous reports, the independent predictors for major bleeding after DES implantation in patients with ACS were anemia, CHF on admission, STEMI presentation, and LAD culprit ACS in the current study. On the other hand, antithrombotic agents and gastric mucosal protective agents such as PPI and H2 blockers were not significantly associated with the risk for major bleeding in the current study, although the observational study design and limited number of patients enrolled in the current study precluded drawing any definitive conclusions about the effects of those agents on bleeding events after DES implantation. ${ }^{21}$

Fatal bleeding, however, occurred in only 4 patients $(0.7 \%)$ over the entire study period. Moreover, 2 of the 4 patients had early in-hospital death from causes unrelated to the type of stent or DAPT, but related to a critically ill status requiring resuscitation upon admission. The acceptably low incidence of fatal bleeding in the current study might support DES use in ACS patients in daily clinical practice.

The current clinical guidelines for ACS recommended that DAPT should be continued for at least 1 year after PCI using either BMS or DES in ACS patients. ${ }^{3}$ Therefore, another possible concern regarding DES use in ACS patients is the risk of adverse cardiovascular events after early DAPT discontinuation because of bleeding. ${ }^{22,23}$ In the current study, the incidence of major bleeding was relatively low (5.2\% at 1 year) despite aggressive use of DES, and no cardiovascular events occurred after DAPT discontinuation in patients with major bleeding. However, the number of patients enrolled in the current study was limited, which precluded drawing any definitive conclusions.

On the other hand, the majority of patients who suffered from major bleeding had been continuing DAPT at the time of bleeding, and approximately half of the patients continued prolonged DAPT beyond 1 year after DES implantation in the current study. Actually, approximately $30 \%$ of major bleeding events occurred beyond 1 year after ACS in the current study, although a significant proportion of the major bleeding events occurred in the perioperative period. Therefore, the appropriate DAPT 
duration should be determined for each patient after considering the net benefit of prolonged DAPT balancing the thrombotic and bleeding risks. Finally, DES use might provide a favorable outcome without much safety concerns in a wide range of ACS patients in real-world practice.

\section{Study Limitations}

There are several important limitations to this study. First, and most importantly, this single-center observational study did not have a control group treated with BMS. However, the vast majority of patients in the present study received DES as the hospital's default strategy, and therefore, the safety of DES use in ACS patients could be evaluated in real-world clinical practice. Second, the higher prevalence of first-generation DES use and routine follow-up angiography in the current study might have influences the clinical outcomes, the TLR rate in particular. Third, use of the GUSTO definition might be inappropriate for evaluating perioperative bleeding events. Finally, because the demographics, practice patterns, and clinical outcomes of ACS patients who undergo PCI in Japan may differ from those outside Japan, generalizing these results to populations outside Japan should be done with caution.

\section{Conclusions}

DES implantation provided favorable long-term clinical outcomes with an acceptable low incidence of fatal bleeding in a real-world population of ACS patients. However, prolonged DAPT seemed to be associated with major bleeding after DES implantation.

\section{References}

1. Sabate M, Cequier A, Iñiguez A, Serra A, Hernandez-Antolin R, Mainar V, et al. Everolimus-eluting stent versus bare-metal stent in ST-segment elevation myocardial infarction (EXAMINATION): 1 year results of a randomised controlled trial. Lancet 2012; 380: 1482 1490.

2. Raber L, Kelbaek H, Ostojic M, Baumbach A, Heg D, Tuller D, et al. Effect of biolimus-eluting stents with biodegradable polymer vs bare-metal stents on cardiovascular events among patients with acute myocardial infarction: The COMFORTABLE AMI randomized trial. JAMA 2012; 308: 777-787.

3. O'Gara PT, Kushner FG, Ascheim DD, Casey DE Jr, Chung MK, de Lemos JA, et al. 2013 ACCF/AHA guideline for the management of ST-elevation myocardial infarction: Executive summary: A report of the American College of Cardiology Foundation/American Heart Association Task Force on Practice Guidelines: Developed in collaboration with the American College of Emergency Physicians and Society for Cardiovascular Angiography and Interventions. Catheter Cardiovasc Interv 2013; 82: E1 -E27, doi:10.1002/ccd.24776.

4. Serruys PW, Unger F, Sousa JE, Jatene A, Bonnier HJ, Schonberger JP, et al. Comparison of coronary-artery bypass surgery and stenting for the treatment of multivessel disease. N Engl J Med 2001; 344: $1117-1124$.

5. Cutlip DE, Windecker S, Mehran R, Boam A, Cohen DJ, van Es GA, et al. Clinical end points in coronary stent trials: A case for standardized definitions. Circulation 2007; 115: 2344-2351.

6. The GUSTO Investigators. An international randomized trial comparing four thrombolytic strategies for acute myocardial infarction. N Engl J Med 1993; 329: 673-682.

7. Spaulding C, Henry P, Teiger E, Beatt K, Bramucci E, Carrie D, et al. Sirolimus-eluting versus uncoated stents in acute myocardial infarction. N Engl J Med 2006; 355: 1093-1104.

8. Menichelli M, Parma A, Pucci E, Fiorilli R, De Felice F, Nazzaro M, et al. Randomized trial of sirolimus-eluting stent versus bare-metal stent in acute myocardial infarction (SESAMI). J Am Coll Cardiol 2007; 49: 1924-1930.

9. Stettler C, Wandel S, Allemann S, Kastrati A, Morice MC, Schömig $\mathrm{A}$, et al. Outcomes associated with drug-eluting and bare-metal stents:
A collaborative network meta-analysis. Lancet 2007; 370: 937-948.

10. Ejiri K, Ishihara M, Dai K, Miki T, Inoue I, Kawagoe T, et al. Threeyear follow-up of sirolimus-eluting stents vs. bare metal stents for acute myocardial infarction. Circ J 2012; 76: 65-70.

11. Kalesan B, Pilgrim T, Heinimann K, Raber L, Stefanini GG, Valgimigli $\mathrm{M}$, et al. Comparison of drug-eluting stents with bare metal stents in patients with ST-segment elevation myocardial infarction. Eurn Heart J 2012; 33: 977-987.

12. Kimura T, Morimoto T, Furukawa Y, Nakagawa Y, Kadota K, Iwabuchi M, et al. Long-term safety and efficacy of sirolimus-eluting stents versus bare-metal stents in real world clinical practice in Japan. Cardiovasc Interv Ther 2011; 26: 234-245.

13. Toyoda K, Yasaka M, Iwade K, Nagata K, Koretsune Y, Sakamoto $\mathrm{T}$, et al. Dual antithrombotic therapy increases severe bleeding events in patients with stroke and cardiovascular disease: A prospective, multicenter, observational study. Stroke 2008; 39: 1740-1745.

14. Eikelboom JW, Mehta SR, Anand SS, Xie C, Fox KA, Yusuf S. Adverse impact of bleeding on prognosis in patients with acute coronary syndromes. Circulation 2006; 114: 774-782.

15. Subherwal S, Bach RG, Chen AY, Gage BF, Rao SV, Newby LK, et al. Baseline risk of major bleeding in non-ST-segment-elevation myocardial infarction: The CRUSADE (Can Rapid risk stratification of Unstable angina patients Suppress ADverse outcomes with Early implementation of the ACC/AHA Guidelines) Bleeding Score. Circulation 2009; 119: 1873-1882.

16. Mehta SK, Frutkin AD, Lindsey JB, House JA, Spertus JA, Rao SV, et al. Bleeding in patients undergoing percutaneous coronary intervention: The development of a clinical risk algorithm from the National Cardiovascular Data Registry. Circ Cardiovas Interv 2009; 2: $222-$ 229.

17. Moukarbel GV, Signorovitch JE, Pfeffer MA, McMurray JJ, White $\mathrm{HD}$, Maggioni AP, et al. Gastrointestinal bleeding in high risk survivors of myocardial infarction: The VALIANT Trial. Eur Heart J 2009; 30: $2226-2232$.

18. Manoukian SV. Predictors and impact of bleeding complications in percutaneous coronary intervention, acute coronary syndromes, and ST-segment elevation myocardial infarction. Am J Cardiol 2009; 104: $9 \mathrm{C}-15 \mathrm{C}$

19. Mehran R, Pocock S, Nikolsky E, Dangas GD, Clayton T, Claessen $\mathrm{BE}$, et al. Impact of bleeding on mortality after percutaneous coronary intervention results from a patient-level pooled analysis of the REPLACE-2 (randomized evaluation of PCI linking angiomax to reduced clinical events), ACUITY (acute catheterization and urgent intervention triage strategy), and HORIZONS-AMI (harmonizing outcomes with revascularization and stents in acute myocardial infarction) trials. JACC Cardiovasc Interv 2011; 4: 654-664.

20. Suh JW, Mehran R, Claessen BE, Xu K, Baber U, Dangas G, et al. Impact of in-hospital major bleeding on late clinical outcomes after primary percutaneous coronary intervention in acute myocardial infarction the HORIZONS-AMI (Harmonizing Outcomes With Revascularization and Stents in Acute Myocardial Infarction) trial. $J$ Am Coll Cardiol 2011; 58: 1750-1756.

21. Chitose T, Hokimoto S, Oshima S, Nakao K, Fujimoto K, Miyao Y, et al. Clinical Outcomes following coronary stenting in Japanese patients treated with and without proton pump inhibitor. Circ J 2012; 76: $71-78$.

22. Kimura T, Morimoto T, Nakagawa Y, Tamura T, Kadota K, Yasumoto $\mathrm{H}$, et al. Antiplatelet therapy and stent thrombosis after sirolimuseluting stent implantation. Circulation 2009; 119: 987-995.

23. Spertus JA, Kettelkamp R, Vance C, Decker C, Jones PG, Rumsfeld JS, et al. Prevalence, predictors, and outcomes of premature discontinuation of thienopyridine therapy after drug-eluting stent placement: Results from the PREMIER registry. Circulation 2006; 113: $2803-$ 2809.

\section{Supplementary Files}

Supplementary File 1

Table S1. Comparison of baseline characteristics of ACS patients with or without major bleeding during 5-year follow-up after PCI with DES

Figure S1. Cumulative incidence of (A) major bleeding and (B) stent thrombosis at 1 year after DES implantation for ACS in the on- and off- DAPT groups of patients.

Please find supplementary file(s);

http://dx.doi.org/10.1253/circj.CJ-13-1388 